\title{
Might a psychosocial approach improve our understanding of itching and scratching?
}

Herbert M. Adler

Thomas Jefferson University

Follow this and additional works at: https://jdc.jefferson.edu/phbfp

Part of the Medicine and Health Commons

Let us know how access to this document benefits you

\section{Recommended Citation}

Adler, Herbert M., "Might a psychosocial approach improve our understanding of itching and scratching?" (2003). Department of Psychiatry and Human Behavior Faculty Papers. Paper 3. https://jdc.jefferson.edu/phbfp/3

This Article is brought to you for free and open access by the Jefferson Digital Commons. The Jefferson Digital Commons is a service of Thomas Jefferson University's Center for Teaching and Learning (CTL). The Commons is a showcase for Jefferson books and journals, peer-reviewed scholarly publications, unique historical collections from the University archives, and teaching tools. The Jefferson Digital Commons allows researchers and interested readers anywhere in the world to learn about and keep up to date with Jefferson scholarship. This article has been accepted for inclusion in Department of Psychiatry and Human Behavior Faculty Papers by an authorized administrator of the Jefferson Digital Commons. For more information, please contact: JeffersonDigitalCommons@jefferson.edu. 


\author{
Author \\ Herbert M. Adler, M.D., Ph.D. \\ Clinical professor in the Departments of Family Medicine and of Psychiatry, \\ Jefferson Medical College \\ The Jefferson Building \\ Suite 10001015 Chestnut Street \\ Philadelphia, PA. 19107 \\ Phone (215) 925-3385 \\ Fax (215) 925-3385 \\ E-mail: herbert.adler@earthlink.net
}

Title

Might a Psychosocial Approach Improve our Understanding of Itching and Scratching?

Key Words: psychosocial, itch, scratch 
What is a psychosocial approach?

An understanding of human behavior can be approached from three overlapping but separable perspectives. Biology addresses the body; psychology addresses the mind; and psychosocial addresses the fact that man is a social animal normally engaged in actual or imagined social interaction. These are complementary, not alternative approaches. The psychosocial approach takes social relationships and the communications that sustain them as the unit of analysis. Much of this interpersonal communication is conveyed via nonverbal body movements that occur without conscious awareness $^{1}$ and are homologous ${ }^{2}$ (sharing both a common evolutionary history and function) with the communicative body movements of nonhuman social animals. ${ }^{3}$ The psychosocial approach to itching and scratching in humans draws on evidence that scratching behavior in nonhuman social animals is sometimes a response to "thwarted urges,"4 and considers the proposition that a similar process may occur in humans. Why add another approach?

There is a parlor game which demonstrates that the only way to connect nine dots, configured as a $3 \times 3$ square, with four contiguous lines is "to go outside the box." A similar paradigm shift might be necessary to encompass features of itching and scratching that are not fully explainable within a biologic and/or psychologic framework. ${ }^{5,6}$ Among these are the observations that scratching can occur in the absence of an itch ${ }^{7,8}$ and is a regular component of normal social interaction. ${ }^{4,9,10}$ Other insufficiently explained features of itching and scratching are so-called pruritic curiosities_- "piano player's practice pruritus," "tycoon pruritus," and "thinker's Itch"11,12 — and how and why 
scratching actually relieves itching, ${ }^{13,}{ }^{14}$ especially when the itch-scratch sequence is triggered by frustration and anger. ${ }^{15}$

It is proposed that these otherwise anomalous features may be encompassed by a paradigm shift that gets outside the body and looks at some instances of itching and scratching from a psychosocial perspective as behavior that has social determinants and may have a social function. The potential value of such a paradigm shift is illustrated by what it has contributed to our understanding of the bodily sensation of feeling tickled. Because people cannot tickle themselves, tickling is only partially explainable within the framework of neurophysiologic mechanisms. ${ }^{16,17}$. However, the explanation is completed by adding the psychosocial determinants because the touch that tickles is a social message, and the ensuing laughter is a social response. Touching vulnerable parts of the body, in both humans and nonhuman primates, leads to laughter only when it is experienced as a mock attack from someone else who is both familiar and safe. The accompanying laughter is an evolutionarily evolved confirmation ${ }^{18}$ that this is a shared social context of play and that no counterattack will be forthcoming. ${ }^{19,20}$

\section{$\underline{\text { Suggestive Evidence }}$}

While there have been no experiments that have tested the hypothesis that itching and scratching function the same way in the social interaction of humans as for some nonhuman social animals, several convergent lines of evidence suggest that this may be the case.

1. When some nonhuman social animals are frustrated by a predicament regarding whether fight or flight is their best course of action, they perform intention and displacement behaviors-incomplete, preparatory, or displacement movements. ${ }^{21}$ For 
example, cattle who are uncertain about whether or not to charge may paw the ground. In similar circumstances, some nonhuman primates characteristically displace the urge to attack onto their own body and scratch themselves. ${ }^{22,23}$ These behaviors appear to serve two functions. First, they may relieve distress by providing a mini-discharge of the sensorimotor urge to act. ${ }^{23,24}$ Second, they provide a visible display which serves as a warning signal to the group that they are poised in the fightflight mode. ${ }^{21,23}$ The social function of this signal is to give a potentially cooperative perceiver a chance to change its antagonistic behavior so that neither fight nor flight is necessary. ${ }^{21}$ In nonhuman social animals, such signals play an important social regulatory role in a nonverbal communication system designed to avert destructive internecine clashes.

2. Similar appearing fidgety intention and displacement movements are observed in humans thwarted by "the behavioral stalemate of contradictory urges." ${ }^{4}$ p. 181 They include tension smoking, drinking when not thirsty, eating when not hungry, smoothing of unruffled hair, face pulling, earlobe tugging, lint picking, playing with bracelets, skin picking, and body scratching. It is common for humans to displace and display constrained anger by pounding on a table with a fist, drumming with fingers on a desk, kicking an object, and, as Koblenzer, ${ }^{25}$ Musaph,${ }^{26}$ and Fried $^{27}$ report, scratching themselves.

3. There are a number of pan human, nonverbal, communicative behaviors affecting social relationships that also occur in nonhuman primates, evidencing their common origins in primate evolution. ${ }^{28}$ These include greeting ceremonies, the appeasement grin, dominant and submission postures, and happy and sad facial expressions, among 
many others. ${ }^{3,29,30}$ So the occurrence of body scratching behavior as a regular part of the social interaction of social-living macaques m $^{22,31,32}$ and similar appearing behavior in conventional human interaction suggests a common social regulatory function for both. Body scratching in social-living macaques is such a reliable signal of what is labeled anxiety, that it has been used as an index behavior to assess the effectiveness of lorazepam, an anxiolytic agent. ${ }^{22,32}$ However, it is relevant to the next line of suggestive evidence to note that while the scratching is an observable, reliable social signal, the "anxiety" is a psychological construct inferred from human experience. As introspective, verbal humans, we are justified in attributing scratching behavior to psychological determinants, but its social regulatory role in some nonhuman primates suggests that it may likewise have psychosocial determinants in humans.

4. The same clinical observations that support the contribution of psychological determinants to scratching behavior - whether anxiety, ${ }^{13,33}$ depression, ${ }^{34-36}$ the need for social approval, ${ }^{37}$ a lack of assertiveness associated with ineffectiveness in expressing anger, ${ }^{15}$ and self-blame and anger displaced into self-destructiveness ${ }^{25}$ could likewise provide support for psychosocial determinants, if the observations also included the relevant social contexts. This would be justified because psychological reactions are regularly a response to actual or imagined social contexts. ${ }^{38}$ In consequence, these psychological determinants would more comprehensively be described as psychosocial determinants. So we may already have a body of clinical observations that could be used to support a psychosocial approach.

5. The autonomic arousal associated with the fight-flight reaction can result in vasomotor changes involving the skin, as in blushing, ${ }^{33}$ engorgement of the lining of 
the nasal cavity, as in an itchy nose ${ }^{39}$ and piloerection in response to both thermoregulatory processes ${ }^{21}$ and fear. ${ }^{40}$ These sensations may be experienced as an itch that elicits a scratch. ${ }^{41}$

6. While the psychosocial implications contained in colloquial expressions, such as "pain in the neck," "oh my aching back," "I can’t stomach it," and "heartache," among many others, may once have been dismissed as unsubstantiated folk beliefs, many have proven to be remarkably prescient. Long before there was scientific proof that we respond to psychosocial stressors with patterned autonomic and musculoskeletal behaviors, common parlance had already given it the imprimatur of common sense. This could reasonably have been expected because such colloquial expressions reflect innumerable, accumulated observations of the correlation of bodily symptoms with psychosocial responses. More relevantly, referring to someone as an "itch," typically denotes an annoying person who provokes in us an urge to attack that is thwarted by social circumstances. While correlation is not causation, it is a precondition of and a clue to causation. So the accumulated observations embodied in common experience that an annoying person is an "itch" (also in other languages) should be regarded as a probable correlation that is worthy of a scientific inquiry into its causes. While the scratching behavior exhibited by frustrated humans can be attributed to psychological determinants, ${ }^{42,43}$ the presence of similar appearing behavior in nonhuman social animals in response to a social predicament of threat in which neither fight nor flight is feasible, ${ }^{21-23,31,32}$ justifies the consideration of a complementary psychosocial explanation.

\section{$\underline{\text { Discussion }}$}


Two major justifications have been put forward for adding a psychosocial approach to our biologic and psychologic explorations of itching and scratching. The first, is that it adds the otherwise missing psychosocial dimension to our understanding of human experience. The second is its power to account for clinical observations that are otherwise anomalous. When scratching behavior is a fidgety intention, displacement movement in response to thwarted urges, it needn't necessarily be associated with an itch nor dermatopathology. Such scratching behavior could provide relief in the same way that the drumming of fingers on a desk provides relief_-via a motor discharge of tension. For example, when a pensive man drums his fingers on his desk, even when alone, we do not examine the desk to account for the behavior. Rather, we recognize the drumming as a fidgetiness that displaces and displays frustration. So "thinker's Itch"11, 12 may sometimes be recast as "thinker's scratch." However, the frustration of thwarted urges can also result in an itch that leads to a scratch because of the cutaneous sensations generated by an autonomic arousal. ${ }^{21,44}$ To propose that itching and scratching may have psychosocial determinants is not to set aside the biological ${ }^{45}$ and psychological ${ }^{25}$ explanations, but it is to recognize their incompleteness.

\section{$\underline{\text { Future Directions }}$}

Whether scratching behavior performs the same social regulatory function in humans as it does in some nonhuman social animals has not been systematically studied. However, the common experience of feeling discomfited in the presence of a fidgety person and the prevalence of scratching behavior in normal social interaction suggest that such a study might provide clinically useful information. Furthermore, since scratching is only one of a variety of intention, displacement, display movements available to the 
frustrated person, what are the psychological and biological determinants that influence its selection.

\section{$\underline{\text { Treatment implications }}$}

A clinical assessment of the causes of itching and scratching might be benefited by including the possibility that they are indicative that the patient is frustrated by thwarted urges, and the source of frustration may be social. In addition to specific biomedical and psychological remedies, treatment might benefit from helping the patient identify possibly etiologic social contexts and find noninjurious alternatives for coping with them. 
1. Birdwhistell R. Kinesics and Context. Philadelphia: University of Pennsylvania Press; 1970.

2. Reite M, Short R, Seiler C, Pauley J. Attachment, loss, and depression. J. Child Psychol. Psychiat. 1981;22:141-169.

3. Bolin R, Bolin S. Sociobiology and sociology: issues in applicability. In: Barchas P, ed. Social Hierarchies: Essays Toward a Sociophysiological Perspective. Westport, Connecticut: Greenwood Press; 1984:3-22.

4. Morris D. Manwatching, A Field Guide to Human Behavior. New York: Harry N. Abrahams, Inc.; 1977.

5. McMahon S, Koltzenburg M. Itching for an explanation. Trends in Neurosciences. 1992;15(12):497-501.

6. Rees J, Laidlaw A. Pruritus: more scratch than itch. Clinical \& Experimental Dermatology. 1999;24(6):490-493.

7. Fruensgaard K. Psychotherapeutic strategy and neurotic excoriations. International Journal of Dermatology. 1991;30(3):198-203.

8. Savin J. How should we define itching? Journal of the American Academy of Dermatology. 1998;39(2):268-269.

9. Goffman E. Interaction Ritual. London: The Penguin Press; 1967.

10. Ekman P, Friesen W. Hand movements. J. Communication. 1972;22:353-374.

11. Bernhard J. Pruritic curiosities. In: Bernard J, ed. Itch Mechanisms and Management of Pruritus. New York: McGraw-Hill; 1994:203-210. 
12. Bernhard J. The itchy scalp and other pruritic curiosities. Seminar in Dermatology. 1995;14(4):326-329.

13. Bernhard J. Scratching. In: Bernard J, ed. Itch Mechanisms and Management of Pruritus. New York: McGraw-Hill; 1994:91-102.

14. Moore P. Patients presenting with pruritus. The Practitioner. 1995;239 (1546):5861.

15. Ginsburg I, Prystowsky J, Kornfeld D, Wolland H. Role of emotional factors in adults with atopic dermatitis. International Journal of Dermatology. 1993;32(9):656-660.

16. Blakemore S, Wolpert D, Frith C. Why can't you tickle yourself? Neuroreport. 2000;11(11:R):11-16.

17. Blakemore S, Wolpert D, Frith C. Central cancellation of self-produced tickle sensation. Nature Neuroscience. 1998;1(7):635-640.

18. Ramachandran V. The neurology and evolution of humor, laughter, and smiling: the false alarm theory. Medical Hypotheses. 1998;51(4):351-354.

19. Hofer M. The Roots of Human Behavior, An Introduction to the Psychobiology of Early Development. San Francisco: W. N. Freeman; 1981a.

20. Eibl-Eibesfeldt I. Human Ethology. Hawthorne, NY: Aldine de Gruyter; 1989.

21. Hinde R. The Biological Bases of Human Behavior. New York: McGraw-Hill; 1974.

22. Schino G, Perretta G, Taglioni A, Monaco V, Troisi A. Primate displacement activities as an ethopharmacological model of anxiety. Anxiety. 1996;2(4):186191. 
23. Tinbergen N. Derived activities; Their causation, function, and origin. Quart. Rev. Biol. 1952;27.

24. Berry D, Pennebaker J. Nonverbal and verbal emotional expression and health. Psychotherapy \& Psychosomatics. 1993;59(1):11-19.

25. Koblenzer C. Neurotic excoriations and dermatitis artefacta. Dermatologic Clinics. 1996;14(3):447-455.

26. Musaph H. Psychodynamics in itching states. Int. J. Psycho-Anal. 1968;49:336340.

27. Fried R. Evaluation and treatment of "psychogenic" pruritus and self-excoriation. Journal of the American Academy of Dermatology. 1995;30(6):993-999.

28. Wilson EO. Sociobiology: The New Synthesis. Cambridge, MA: Harvard University Press; 1975.

29. Ekman P. Strong evidence for universals in facial expressions: a reply to Russell's mistaken critique. Psychological Bulletin. 1994;115(2):268-287.

30. Konner M. Anthropology and Psychiatry. In: Kaplan H, Saddock B, eds. Comprehensive Textbook of Psychiatry/VI. Vol VI. Baltimore: Williams and Wilkins; 1995:337-355.

31. Troisi A, Schino G, D'Antoni M, Pandolfi N, Aureli F, D'Amato F. Scratching as a behavioral index of anxiety in macaque mothers. Behavioral \& Neural Biology. $1991 ; 56(3): 307-313$.

32. Schino G, Troisi A, Perretta G, Monaco V. Measuring anxiety in nonhuman primates: effect of lorazepam on macaque scratching. Pharmacology, Biochemistry \& Behavior. 1991;38(4):889-891. 
33. Medansky RS, Handler RM. Dermatopsychosomatics: classification, physiology, and therapeutic approaches. Journal of the American Academy of Dermatology. $1981 ; 5(2): 125-136$.

34. Gupta M, Gupta A, Schork N, Ellis C. Depression modulates pruritus perception: a study of pruritus in psoriasis, atopic dermatitis, and chronic idiopathic urticaria. Psychosomatic Medicine. 1994;56(1):36-40.

35. Greco P, Ende J. Pruritus: a practical approach. Journal of General Internal Medicine. 1992;7(3):340-349.

36. Laihinen A. Assessment of psychiatric and psychosocial factors disposing to chronic outcome of dermatoses. Acta Dermato-Venereologica. Supplementum. $1991 ; 156: 46-48$.

37. Gupta M, Gupta A, Ellis C, Voorhees J. Some psychosomatic aspects of psoriasis. Advances in Dermatology. 1990;5:21-30; discussion 31.

38. Kemper T. Social relational determinants of emotion and physiology. In: Barchas P, Mendoza S, eds. Social Cohesion. Westport, Conn: Greenwood Press; 1984:101-120.

39. Hirsch AR, Wolf CJ. Practical methods for detecting mendacity: a case study. Journal of the American Academy of Psychiatry \& the Law. 2001;29(4):438-444.

40. Clark J, Rager D, Calpin J. Animal well-being II. Stress and distress. Laboratory Animal Science. 1997;47(6):571-579.

41. Moschella SL, Hurley HJ. Dermatology. Third ed. Philadelphia: W. B. Saunders Company; 1991. 
42. Koblenzer C. Psychological and psychiatric aspects of itching. In: Bernhard J, ed. Itch Mechanisms and Management of Pruritus. New York: McGraw-Hill; 1994:347-366.

43. Musaph H. Itching and Scratching, Psychodynamics in Dermatology. Philadelphia: F. A. Davis Company; 1964.

44. Bastock M, Morris D, Moynihan M. Some comments on conflict and thwarting in animals. Behavior Genetics. 1953;6:66-84.

45. Greaves MW, Wall PD. Pathophysiology of itching. The Lancet. 1996;348(9032):938-940. 